\title{
Knowledge management in knowledge-intensive organisations: Understanding its benefits, processes, infrastructure and barriers
}

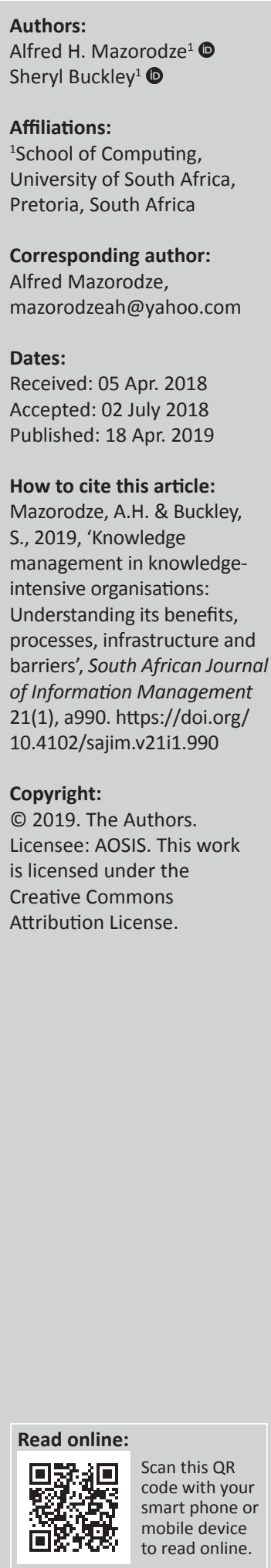

Background: Knowledge management aims to improve organisational performance and it marks the beginning of organisational transformation. Most knowledge-intensive organisations engage and practise knowledge management without a full understanding of its benefits. A knowledge-intensive organisation is an organisation whose services and operations are heavily reliant on professional knowledge. The study, therefore, provides a solid understanding of knowledge management benefits, processes, infrastructure and barriers in knowledge-intensive organisations.

Objectives: To understand knowledge management, its benefits, processes, infrastructure and barriers in knowledge-intensive organisations. The research objectives extend our understanding of knowledge management in organisations, identify and describe knowledge management benefits. Identification of the most important knowledge management process and associated infrastructure are among other objectives.

Method: A survey was used to solve the problem. A structured questionnaire was used to collect quantitative data from 112 participants from knowledge-intensive firms in Namibia. The quantitative data were analysed using Microsoft Excel 2013 spreadsheet package.

Results: The study has revealed that the prime benefit of knowledge management in knowledge-intensive organisations is to allow improved knowledge flow, thereby enhancing the capability of the organisation to manage change with more than $50 \%$ representation of the participants. In addition to that, the study also found that knowledge sharing is the most important knowledge management process, among other processes such as knowledge creation, knowledge capture and knowledge reuse. All the participants (100\%) concurred that a flat organisational structure supports knowledge sharing. The research findings have further discovered that the biggest barrier to effective knowledge management is the lack of budget to support knowledge management efforts. This was represented by $67.9 \%$ of the participants. Lack of executive support and lack of time were also among the great barriers with $57.1 \%$ and $52.7 \%$, respectively.

Conclusion: Knowledge management allows improved knowledge flow in knowledge-intensive organisations. We can, therefore, conclude that the participants believed that knowledge sharing is more important than creation, capturing, transferring and reuse. It is, therefore, important to underscore that knowledge sharing should be taken as a priority if organisations are to remain competitive. Research results have also revealed that a flat organisational structure is the best for knowledge sharing. For improved organisational performance, knowledge management barriers must be removed with the assistance of management.

Keywords: Knowledge management; knowledge sharing; management barriers; organisational performance; communities of practice.

\section{Introduction}

Knowledge management (KM) in organisations has the principal goal of improving organisational performance (Schiuma 2012). Knowledge management has developed from a premature concept to an organisational need, especially in this 21st century which is highly dependent on technology. According to Namibia Vision 2030 (Government of the Republic of Namibia 2004), one of the national objectives is to transform Namibia into a knowledge-based, highly competitive and industrialised nation with sustainable economic growth. This objective could be achieved if professional skills are transferred from experts to non-experts through KM. Most institutions in Namibia, such as government departments, universities, hospitals and other small and medium 
enterprises, do not exhibit evidence of what KM entails (Government of the Republic of Namibia 2004). Some of these organisations engage $\mathrm{KM}$ practices without a full understanding that they are participating in KM. A knowledge-intensive organisation is defined by Nahlinder (2005) as an organisation whose services and operations are heavily reliant on professional knowledge. Universities and consulting engineering firms in this regard are examples of knowledge-intensive firms. This article, therefore, provides a better understanding of what $\mathrm{KM}$ involves in improving organisational performance. The article further analyses the benefits KM brings to organisations and the barriers that distract the KM efforts.

Effective and efficient KM is important in addressing and transforming the way an organisation operates. Knowledge is shared in organisations by means of various social media platforms, face-to-face meetings and focus group discussions (Wang \& Noe 2010). Technology partially supports KM implementation. Knowledge management is a keystone of competitive advantage in today's organisations and it improves the way an organisation is managed. Knowledge management takes advantage of existing expertise and experiences, enabling organisations to leverage their competencies and stimulate growth (Khedhaouria \& Jamal 2015). This article explores the KM benefits, processes, infrastructure and barriers to effective KM in Namibian knowledge-intensive organisations. The rapid advances in information and communication technologies (ICTs) have opened new ways of addressing problems in KM. Information and communication technology is considered by many researchers such as Song (2007) and Soto-Acosta and CegarraNavarro (2016) as a powerful tool for KM success, but ICT alone cannot be the solution. At this moment, ICT is used commendably for data and information processing in organisations but not for KM (Becerra-Fernandez \& Sabherwal 2010). Knowledge management has a great potential for improved organisational performance and transformation in terms of knowledge sharing among employees.

The major source of knowledge is employees with a wealth of experience in their respective fields, but again, it is the extent to which this resource is tapped into, in order to extend the KM capacities of the organisations, that matters (King 2008). Conceding that there are problems associated with knowledge sharing among employees and hence KM is not successfully implemented in most organisations in the developing economies, particularly in Namibia: what progressive steps could be taken in order to overcome such a hurdle? It has been empirically proven that many challenges of KM are now nontechnical (Paraponaris \& Sigal 2015). Some of the barriers to effective KM involve recognition of $\mathrm{KM}$ as an organisational function and lack of executive support as analysed by UjwaryGil (2011, 94-95). Considering all the success factors, tools and technologies, there is still need to explore the extent to which KM improves organisational performance.

The research was conducted with the following aims and objectives:
- To understand KM in knowledge-intensive organisations.

- To identify and describe the benefits of KM in knowledgeintensive organisations.

- Describe the KM processes and the associated KM infrastructure.

- To identify barriers to effective $\mathrm{KM}$ and provide the solutions to overcome the identified barriers.

We, therefore, hypothesised that understanding $\mathrm{KM}$ and its benefits, processes and infrastructure, identification of KM barriers and the subsequent solutions to these barriers may increase organisational performance. The following section gives a brief literature review on KM.

\section{Literature review}

Knowledge management, specifically in this cyber age, has been in existence for over two decades now. The KM concept was started in the 1990s by several theorists such as Nickols (1999), Wiig (1993), McElroy (2003), Rollet (2003), Choo (1996), Bukowitz and Williams (2003), Zack (1996), Davenport and Prusak (1998) and Nonaka and Takeuchi (1995). The flux in information and knowledge has changed the way businesses and social institutions work. Knowledge is considered to be an organisation's largest asset that must be managed effectively. Knowledge management therefore promises and provides models and tools that help organisations to create an environment which supports knowledge sharing. Information and communication technology is currently considered one of the enablers for the effective implementation of KM. Managing knowledge has consequently become an important prospect aimed at creating value in multifaceted organisations.

Nonaka (1994:21) defines knowledge as a 'justified true belief'. It is believed that organisational knowledge is entrenched in processes, procedures, individual employees, systems and culture (Nonaka \& Takeuchi 1995). Most theoretical and practical findings in $\mathrm{KM}$ are hidden from the public because it is normally said that 'knowledge is power', so experts hoard knowledge in order to gain market share. However, other experts share best practices, frameworks and lessons learnt through publication and dissemination of research papers. Research has shown that successful KM improves organisational effectiveness, specifically in knowledge-intensive organisations. What is left now is measuring the extent to which organisational effectiveness becomes a reality after implementation of KM. Such a quantification of organisational effectiveness is sorely missing in current researches. Knowledge can exist in different media and also in multimodal forms. The major sources of knowledge are employees with wealth of experience and high technical skills.

Knowledge can be fixed in organisational routines, procedures and structures. It is needed that organisations must manage their knowledge, as instruments of differentiation, to boost productivity, leverage competitive advantage and spur innovation. Nonaka and Takeuchi (1995) and Davenport and Prusak (1998) have all revealed that the role of knowledge in 
management is value-generation. Having established this point, there is a need for empirical evidence regarding which KM processes work efficiently in selected organisations where the purposes are driven to boost productivity, afford competitive advantage and enhance innovation. In knowledgeintensive organisations such as consulting firms and universities, KM has a great role to play. Universities are dynamically changing and they are involved in the knowledge business. Universities face challenges of high expectations from stakeholders, global competition and technological advances. Researchers like Ebersberger and Altman (2013) argue that universities should reflect their visions and strategies for them to be successful and remain competitive in the global environment.

Knowledge management is defined in engineering as the process through which an enterprise systematically gathers, organises, analyses and shares knowledge relevant to its operating disciplines. The culture and practice of sharing knowledge is rarely practised in such organisations. The process of KM embraces a wide array of organisational, management and technically orientated approaches that support the exploitation of an organisations' intellectual assets. Organisations can also create communities of practice (CoPs) to share knowledge for the benefit of the entire firm. Researchers like Wenger (2014) argue that the probability of sharing knowledge among and within a CoP is very high. Other researchers in $\mathrm{KM}$ have also revealed that knowledge sharing could be eased by a less centralised organisational structure that apparently inhibits such openness (Kim \& Lee 2006). Others have recommended a combination of centralised and decentralised approaches in the organisation's hierarchy contending that organisations should have KM support groups in their structures.

\section{Research design}

A survey was conducted to collect data from the research participants in Oshana region of Namibia. The participants of this research were selected from knowledge-intensive organisations, specifically universities and consulting engineering firms. Two universities were involved, one public and one private. The three consulting firms were all private entities. Quantitative data were collected by paper-based questionnaires that were pretested before administration. Before adaptation and distribution, the questionnaire was standardised to make sure that each section addressed one objective and answered one research question. This tentatively ensured that each question in the entire questionnaire responded to each of the research questions. Responses were compared to a data analysis protocol for purposes of data relevance and consistency. The collected quantifiable scores from the participants were analysed using descriptive statistics. Microsoft Office Excel 2013 spreadsheet package was used for data analysis.

The sample for this study consisted of 112 participants from the knowledge-intensive organisations (universities and consulting engineering firms). The response rate was $100 \%$. Participants were lecturers with similar qualifications and engineers in their respective fields. According to the Research Advisors (2007), a sample of above 100 participants has a 5\% margin of error if tested at 95\% confidence level and that was the rational adopted for this study. This research study was conducted with full reflection on the proper conduct of scientific enquiry. The researcher had the responsibility of protecting the anonymity of the research participants and to store the collected data in a strictly confidential manner. The data obtained from the respondents were kept confidentially and names of all research participants were not divulged. Anonymity and confidentiality were highly considered in this study, ensuring that the ethical principles in research are followed as highlighted by Babbie et al. (2010) on the codes of good research practice.

\section{Results}

A total of 112 questionnaires were distributed and all of them were returned by the research participants. Mixed results were obtained on the most important benefit of KM from an organisational perspective. The question asked was, 'Which of the following KM benefits do you think is the most important?' Table 1 shows the responses obtained from the 112 participants. The results show that $52.7 \%$ of the participants concur that KM improves knowledge flow and enhances the capability of the organisation to manage change.

On the KM processes, participants were asked to rank the importance of the five KM processes in their daily work activities: creation, capturing, sharing, transferring and reuse. These processes were drawn from a thorough literature review by various authors such as Becerra-Fernandez and Sabherwal (2010), Wiig (2004), Dalkir (2005), Davenport and Harris (2007) and Stewart and Mansingh (2010) just to mention some. After collecting the responses, answers were entered into Microsoft Office Excel 2013 spreadsheet package for analysis. The findings are presented in Figure 1.

According to the results, it has been revealed that the most important KM process is knowledge sharing with $61.54 \%$ representation. This was followed by knowledge capturing process with $21.19 \%$. All the other KM processes (creation, reuse and transferring) recorded less than $20 \%$ of importance. To be specific, they were as follows: knowledge creation (10.9\%), knowledge reuse $(14.13 \%)$ and knowledge transfer (6.5\%).

As $\mathrm{KM}$ is facilitated by $\mathrm{KM}$ infrastructure, the participants were further asked a question related to the organisational

TABLE 1: Benefits of knowledge management in knowledge-intensive organisations.

\begin{tabular}{|c|c|c|}
\hline Knowledge management benefit & $\begin{array}{l}\text { Number of } \\
\text { participants }\end{array}$ & Percentage \\
\hline $\begin{array}{l}\text { - KM accelerates innovation and strengthens } \\
\text { organisational commitment. }\end{array}$ & 18 & 16.0 \\
\hline $\begin{array}{l}\text { - KM creates competitive advantage in } \\
\text { organisations. }\end{array}$ & 7 & 6.3 \\
\hline $\begin{array}{l}\text { - KM improves knowledge flow and enhances the } \\
\text { capability of the organisation to manage change. }\end{array}$ & 59 & 52.7 \\
\hline $\begin{array}{l}\text { - KM avoids repetition of tasks by promoting } \\
\text { knowledge reuse. }\end{array}$ & 17 & 15.1 \\
\hline $\begin{array}{l}\text { - KM enhances coordination and collaboration } \\
\text { among employees. }\end{array}$ & 11 & 9.8 \\
\hline
\end{tabular}

$\mathrm{KM}$, knowledge management. 


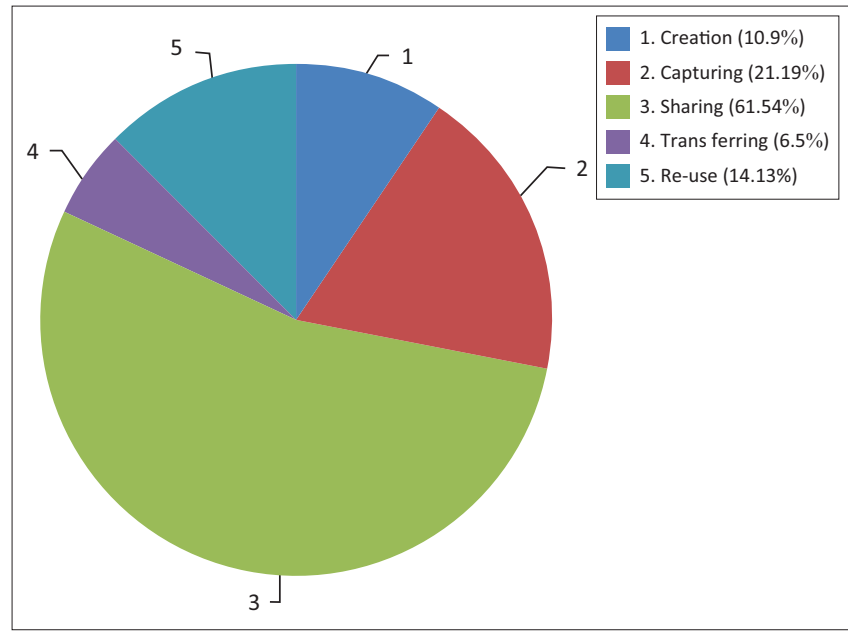

FIGURE 1: Importance of the knowledge management processes.

structure. The research question asked on this section was: 'for knowledge to be shared among co-workers, which type of organisational structure do you think will be best?' The response was between a hierarchical organisational structure and a flat organisational structure. All the participants (100\%) highlighted that a flat organisational structure will be the best for knowledge sharing.

On the barriers to effective $\mathrm{KM}$, respondents were allowed to choose as many barriers as possible. According to this case study conducted in Namibian knowledge-intensive organisations, the greatest barrier to effective $\mathrm{KM}$ was the lack of budget to support KM undertakings. Table 2 indicates the barriers to effective $\mathrm{KM}$ and the responses elicited from the participants. The question was, 'which of the following barriers greatly affect the KM implementation at your institution?'

It has been clearly revealed that lack of budget to support KM efforts is the greatest barrier to effective KM. Data collected show that $67.9 \%$ of the respondents identified lack of budget support as a major barrier. Lack of executive support was the second barrier, with $57.1 \%$ of the participants. Lack of time, motivation and rewards recorded $52.7 \%$. All the other barriers such as resistance to change, prohibitive organisational structures, inefficient communication, lack of knowledge sharing culture, lack of technological infrastructure, lack of trust, differences in education levels, lack of clear return on investment and lack of appropriate methodologies recorded less than $50 \%$ of the participants.

\section{Discussion}

The study has revealed that improvement of knowledge flow and enhancement of capabilities to manage change is a major benefit of KM in knowledge-intensive organisations. Accelerating innovation and strengthening organisational commitment were also seen as important organisational benefits. It was also found that $\mathrm{KM}$ helps in avoiding repetition of tasks. The other benefits such as creating competitive advantage and enhancing coordination and collaboration among employees were equally important. Also, another key
TABLE 2: Analysis of the knowledge management barriers.

\begin{tabular}{lcc}
\hline Knowledge management barrier & $\begin{array}{c}\text { Number of } \\
\text { participants }\end{array}$ & Percentage \\
\hline Lack of executive support & 64 & 57.1 \\
Lack of budget to support KM efforts & 76 & 67.9 \\
Resistance to change & 43 & 38.3 \\
Prohibitive organisational structure & 12 & 10.7 \\
Lack of time, motivation and rewards & 59 & 52.7 \\
Inefficient communication and lack of training & 30 & 26.7 \\
Lack of knowledge sharing culture and cultural & 37 & 33.0 \\
differences & 10 & 8.9 \\
Lack of technological infrastructure & 35 & 31.2 \\
Lack of trust & 6 & 5.3 \\
Differences in levels of education & 17 & 15.1 \\
Lack of clear return on investment & 42 & 37.5 \\
Lack of appropriate methodologies & 15 & 13.3 \\
\hline Other (specify) &
\end{tabular}

$\mathrm{KM}$, knowledge management.

advantage of $\mathrm{KM}$ is that knowledge is shared between employees and is not lost if an employee leaves the organisation for whatever reason. According to a case study conducted in Namibian knowledge-intensive organisations, the prime benefit of KM is that it improves knowledge flow and enhances the capability of the organisation to manage change. This benefit is quite clear and is also supported in the literature where Argote (2016) states that KM is closely aligned with change management.

Knowledge management processes are more people-intensive and less technology-intensive than most practitioners and organisations appreciate. This observation is supported by King (2008) who perceives the common misconception about $\mathrm{KM}$ processes and advises this critical orientation towards KM processes. Knowledge management processes identified by Becerra-Fernandez and Sabherwal (2010) include acquisition, creation, refinement, storage, transfer, sharing and utilisation. In this study, it has been revealed that the most important KM process is knowledge sharing with $61.54 \%$. This was followed by knowledge capturing with $21.19 \%$. All the other KM processes along the spectrum recorded less than $20 \%$ of importance. We can, therefore, conclude that the participants believed that knowledge sharing is more important than creation, capturing, transferring and reuse. This suggests that knowledge sharing in those organisations is minimal. The challenge is thus for leaders to identify root causes and to ensure knowledge sharing solutions are in place, in terms of either methodologies or incentives. It is, therefore, important to underscore that knowledge sharing should be taken as a priority if organisations are to remain competitive. As knowledge creation is a process and knowledge itself is a strategic organisational asset, $\mathrm{KM}$ turns out to be a strategic pillar of enterprises that seek to create value for their shareholders and such a perspective is confirmed by Vasista and Al-Sudiary (2012).

As all the participants $(100 \%)$ revealed that a flat organisational structure is the best for knowledge sharing, we can therefore extrapolate that flattening organisational structures will eliminate organisational layers and promote 
effective KM. Employees can form CoPs to facilitate knowledge sharing. These CoPs can be physical in welldesigned physical environments or can be virtual, using the available information technologies, all aimed at improving organisational performance. Knowledge management is, therefore, conceptualised as a set of approaches and methods, which shows the way to do things. The five major KM infrastructural components in the organisational context are organisational culture, organisational culture, IT infrastructure, leadership and lastly the physical environment (Becerra-Fernandez \& Sabherwal 2010). A hierarchical organisational structure affects the people with whom they collaborate and share knowledge. Flattening organisational structures eliminates organisational layers. Knowledge sharing is highly likely to take place when people are in decentralised organisations where such organisations can use CoPs to facilitate knowledge sharing (Wenger 2014). The probability of sharing knowledge among and within a CoP is very high. We therefore recommend a flat organisational structure for effective KM.

Barriers negatively affect KM efforts in most organisations. Data collected from the knowledge-intensive organisations show that $67.9 \%$ of the respondents identified lack of budget support as a major barrier. From the results, we can conclude that lack of a specific budget targeted at sustained KM was the biggest barrier to effective KM. Future research should look at the specifics of budget required, that is, is it for time that employees need, training interventions, mentoring or investment in additional tools? Overcoming all or most of these barriers could certainly improve organisational performance, which was one of the aims of this research. Lack of budget can be overcome by availing enough finances for the KM undertakings. Executive support is required to create a conducive environment that inspires and supports knowledge sharing and removes the barriers that exist in organisations. Wiig (2004) was of the opinion that organisations appoint KM officers (KMOs), specifically in charge of formulating knowledge policies. Implementation of KM is often blocked by top management's resistance to change, particularly with regard to people, processes and the associated technology. This barrier can be removed by flattening the organisational structures as advised by Riedge (2007) who classified barriers into organisational and technical barriers. The process of overcoming resistance is lengthy and cumbersome. Managers should, therefore, be involved during the initial planning and all parties concerned should be informed as soon as possible to ease fear and anxiety that often accompanies restructuring and change.

\section{Conclusion}

This article provided an understanding of KM in theory and practice. The study has revealed that the prime benefit of $\mathrm{KM}$ is to allow improved knowledge flow in an organisation, thereby enhancing the capability of the organisation to manage change with more than $50 \%$ representation of the participants.
It has been revealed that the most important KM process in knowledge-intensive organisations is knowledge sharing with $61.54 \%$ representation. This was followed by knowledge capturing process with $21.19 \%$ representation. All the other KM processes along the spectrum recorded less than $20 \%$ of importance. We can, therefore, conclude that the participants in knowledge-intensive organisations believed that knowledge sharing is more important than creation, capturing, transferring and reuse. It is therefore important to underscore that knowledge sharing should be taken as a priority if knowledge-intensive organisations are to remain competitive. The research results have also revealed that a flat organisational structure is the best for knowledge sharing. Also, the research findings have further revealed that the biggest barrier to effective KM is the lack of budget to support KM efforts. This was represented by $67.9 \%$ of the participants. Moreover, the lack of executive support and lack of time were also great barriers with $57.1 \%$ and $52.7 \%$, respectively. For improved organisational performance, $\mathrm{KM}$ barriers must be removed with the assistance of management. The knowledge sharing process is very important for all knowledge-intensive organisations.

\section{Acknowledgements}

The authors would like to thank all the participants who participated in this study. They would also like to thank the language specialist who edited this work. Many thanks are also accorded to individuals who assisted but are not mentioned here: your help went a long way in making this research possible.

\section{Competing interests}

The authors declare that they have no financial or personal relationships that may have inappropriately influenced them in writing this article

\section{Authors' contributions}

A.H.M. collected the data from the knowledge-intensive organisations and wrote the article. S.B. assisted in giving direction of the research article. Both authors read and approved the final version of the manuscript.

\section{References}

Argote, L., 2016, 'Knowledge transfer in organizations: The roles of members, tasks, tools and networks', Organizational Behaviour and Human Decision Processes 136, 146-159. https://doi.org/10.1016/j.obhdp.2016.08.003

Babbie, E., Mouton, J., Vorster, P. \& Prozesky, B., 2010, The practice of social research, Oxford University Press, Cape Town.

Becerra-Fernandez, I. \& Sabherwal, R., 2010, Knowledge management systems and processes, Paperback, Armonk, NY.

Bukowitz, W. \& Williams, R., 2003, The knowledge management fieldbook, Prentice Hall, London.

Choo, C.W., 1996, The knowing organization: How organizations use information to construct meaning, create knowledge, and make decisions, Oxford University Press, UK.

Dalkir, K., 2005, Knowledge management in theory and practice, Elsevier ButterworthHeinemann, Oxford.

Davenport, T.H. \& Prusak, L., 1998, Working knowledge: How organisations manage what they know, Harvard Business School Press, Boston, US. 
Davenport, T.H \& Harris, J.G., 2007, Competing on analytics. New science of winning, Harvard Business School, Boston, US

Ebersberger, B. \& Altman, A., 2013, Universities in change: Managing higher education institutions in the age of globalization, Springer-Verlag, New York.

Government of the Republic of Namibia, 2004, Namibia Vision 2030: Policy framework for long-term national development, Office of the President, Windhoek, Namibia.

Khedhaouria, A. \& Jamal, A., 2015, 'Sourcing knowledge for innovation: Knowledge reuse and creation in project teams', Journal of Knowledge Management 19(5), 932-948. https://doi.org/10.1108/JKM-01-2015-0039

Kim, M. \& Lee, J., 2006, 'Effects of managerial drivers and climate maturity on Knowledge Management performance', Information Resources Management Journal 19(3), 48-59. https://doi.org/10.4018/irmj.2006070104

King, W.R., 2008, 'Knowledge management and organisational learning', Annals of Information Systems 4, 3-13. https://doi.org/10.1007/978-1-4419-0011-1_1

McElroy, M.W., 2003, The new knowledge management: Complexity, learning, and sustainable innovation, $\mathrm{KMCl}$ Press, Oxford, ButterworthHeinemann.

Nahlinder, J., 2005, Innovation and employment in services. The case of knowledgeintensive business services in Sweden, Linkoping University, Sweden.

Nickols, F., 1999, The knowledge in knowledge management, Butterworth-Heinemann, Boston, MA.

Nonaka, I., 1994, 'A dynamic theory of organisational knowledge creation', Organization Science 5(1), 14-37. https://doi.org/10.1287/orsc.5.1.14

Nonaka, I. \& Takeuchi, H., 1995, The Knowledge-creating company: How Japanese companies create dynamics of innovation, Oxford University Press, New York.

Paraponaris, C. \& Sigal, M., 2015, 'From knowledge to knowing, from boundaries to boundary construction', Journal of Knowledge Management 19(5), 881-899. https://doi.org/10.1108/JKM-01-2015-0034

Riege, A., 2007, 'Actions to overcome knowledge transfer barriers in MNCs', Journal of Knowledge Management 11(1), 48-67.
Research Advisors, 2007, Sample size table, viewed 30 April 2017, from http://www. research-advisors.com/documents/SampleSize-web.xls

Rollet, H., 2003, Knowledge management: Processes and technologies, Kluwer Academic Publishers, Boston, MA.

Schiuma, G., 2012, 'Managing knowledge for business performance improvement' Journal of Knowledge Management 16(4), 515-522. https://doi.org/10.1108/ 13673271211246103

Song, H., 2007, The role of information and communication technologies in knowledge management: From enabler to facilitator, School of Business Information Technology, RMIT University, Singapore.

Soto-Acosta, P. \& Cegarra-Navarro, J., 2016, 'New ICTs for Knowledge Management in Organizations'. Journal of Knowledge Management 20(3), 417-422.

Stewart, H. \& Mansingh, G., 2010, 'Using knowledge management to assist in the transformation of the Jamaica Constabulary Force', Proceedings of SIG Global Development Third Annual Workshop, Saint Louis, MO.

Ujwary-Gil, A., 2011, 'The analysis of barriers to knowledge management in the organisation', Electronic Journal of Knowledge Management 1, 84-100.

Vasista, T.G.K. \& Al-Sudiary, M.A.T., 2012, 'Fostering knowledge management and citizen participation via e-governance for achieving sustainable balanced development', Journal of Knowledge Management 10(1), 52-64.

Wang, S. \& Noe, R.A., 2010, 'Knowledge sharing: A review and directions for future research', Human Resource Management Review 20, 115-131. https://doi. org/10.1016/j.hrmr.2009.10.001

Wenger, E., 2014, Communities of practice and social learning systems: The career of a concept, Springer Verlag, Open University, London, UK.

Wiig, K., 1993, Knowledge management foundations, Schema Press, Arlington, TX.

Wiig, K., 2004, People-focused knowledge management, Elsevier ButterworthHeinemann, Burlington, VT.

Zack, M.H., 1996, 'Developing a knowledge strategy', California Management Review 41(3), 125-145. https://doi.org/10.2307/4116600 